Гунич С.В.

\title{
КОНСТИТУЦИОННО-ПРАВОВЫЕ АСПЕКТЫ МЕХАНИЗМА ОБЕСПЕЧЕНИЯ НАЦИОНАЛЬНОЙ БЕЗОПАСНОСТИ РОССИЙСКОЙ ФЕДЕРАЦИИ
}

\begin{abstract}
Аннотация: в статье исследуется конституционно-правовой механизм обеспечения состояния защищенности личности, общества и государства от внутренних и внешних угроз. Проводится анализ содержания элементов системы обеспечения национальной безопасности: субъекты обеспечения безопасности; объекты и предмет безопасности; методы и направления обеспечения национальной безопасности. Сравнение правового регулирования их взаимодействия осуществляется исходя из необходимости учета в государственной деятельностиинтересов человека и гражданина, соблюдения приоритета его прав и свобод, повышения и развития гражданской активности личности и их объединений, а также суверенной сплоченности всей нации. Характеристика выделенных элементов раскрывается с позиции соотнесения с конституционно-правовыми принципами построения правового демократического государства и вышей иенности в нем человека, его прав и свобод. Автор приходит к выводу о том, что функиионирование механизма обеспечения начиональной безопасности в Российской Федерации должно осуществляться с опорой на конституционные иенности. Его правовое закрепление с необходимостью должно соответствовать особой значимости человека, его прав и свобод, гражданского мира и согласия, целостности страны, а также баланса интересов личности, общества и государства.

Ключевые слова: начиональная безопасность, баланс интересов, механизм, субъект обеспечения безопасности, объект бозопасности, предмет безопасности, метод обеспечения безопасности, личность, общество, государство.
\end{abstract}

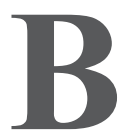

условиях все возрастающей глобализации, обеспечение национальной безопасности признается основополагающим приоритетом развития большинства стран современного мира. Реализация столь сложной задачи находит отражение в деятельности всего механизма государства, проявляя себя, в том числе, в принимаемых государственным аппаратом политически-властных решениях. Совершенно очевидно, в этой связи, что научное осмысление основ теории национальной безопасности, да и практическое ее выражение, неразрывно связаны с политикой, как «искусством управления государством», политической системой а, следовательно, - с наукой и комплексной отраслью конституционного права. Таким образом, ее научно-правовой базис может быть взят за основу при исследовании механизма обеспечения состояния защищенности личности, общества и государства от внутренних и внешних угроз.

В поддержку такого подхода свидетельствует тот факт, что, во-первых, именно на формирование подобного механизма, как справедливо отмечают ученые, долгие годы были направлены усилия различных стран мира при проведении государственной политики в сфере национальной безопасности ${ }^{1}$. Именно данная научно-правовая категория, исходя из ее этимологического значения, способна охарактеризовать систему национальной безопасности во всех ее проявлениях и находящуюся при этом в упорядоченном движении ${ }^{2}$. Именно через категорию

\footnotetext{
См.: Общая теория национальной безопасности: Учебник / Под общ. ред. А.А. Прохожева. Изд. 2 / М.: Изд-во РАГС, 2005. C. 42.

2 См.: Словарь Русского языка. Т. 2. М., 2002. С. 262.
} 


\section{Национальная безопасность - № 4(33) • 2014}

«механизм», как отмечал И. В. Ростовщиков, становится возможным охватить то, или иное явление, представить процесс в системно-динамическом виде ${ }^{3}$. Во-вторых, содержание включаемых в данный механизм элементов с необходимостью затрагивает государственно-властные правоотношения и находит отражение в правовых актах конституционного характера. Сами же эти элементы, так или иначе, связаны со сферой взаимодействия человека, общества и государства, что и составляет основу конституционно-правового регулирования.

Современное развитие конституционных правоотношений исходит из необходимости учета в государственной деятельности интересов человека и гражданина, соблюдения приоритета его прав и свобод, повышения и развития гражданской активности личности и их объединений, а также суверенной сплоченности всей нации. Демократический характер российского государства требует создания и функционирования механизма беспрепятственной реализации свободы воль субъектов этих отношений, основанном на формальном их равенстве. Следствием всего этого явилось развитие в современной российской действительности системы обеспечения национальной безопасности, выполняющей задачу по созданию условий беспрепятственной реализации их интересов. Характеристика отдельных элементов этой системы находит отражение как в юридической науке, так и в практике правового регулирования. Безусловный приоритет при этом, как представляется, приобретают принципы обеспечения безопасности, как основные, руководящие начала функционирования всей системы.

Нормы права, придающие определенную динамику указанной системе, входят в зону конкуренции с конституционными правовыми нормами. Ведь определяя принципы и направления обеспечения безопасности столь значимых субъектов конституционно-правовых отношений, они так или иначе должны учитывать ценности, принимаемые в том или ином государственно-обособленном обществе и возводимые им в статус основ конституционного строя. Таким образом, определенный исследовательский интерес приобретает характеристика элементов механизма обеспечения национальной безопасности и соотнесение их содержания с конституционно-

\footnotetext{
3 См.: Ростовщиков И.В. Права личности в России: их обеспечение и защита органами внутренних дел. Волгоград, 1997. C. 64.
}

правовыми принципами построения правового демократического государства.

Что касается самих элементов, то они получили официальное признание в правовом документе планового характера, закрепляющего, к тому же, основные понятия, используемые при построении и развитии рассматриваемой системы ${ }^{4}$. Его анализ позволяет говорить о выстраивании в Российской Федерации своеобразного механизма обеспечения национальной безопасности, базирующегося на необходимости защиты конституционных ценностей и имеющего в наличии присущие подобного рода деятельности элементы. Особой значимостью среди этих элементов выделяются: субъекты обеспечения безопасности; объекты и предмет безопасности; методы и направления обеспечения национальной безопасности.

Субъекты рассматриваемого механизма определяются в качестве сил обеспечения безопасности, к которым относятся Вооруженные Силы Российской Федерации, другие войска, воинские формирования и органы, в которых федеральным законодательством предусмотрена военная и (или) правоохранительная служба, а также федеральные органы государственной власти, принимающие участие в обеспечении национальной безопасности государства на основании законодательства Российской Федерации. Критический анализ данного круга субъектов уже проводился автором, суть которого свелась, вопервых, к констатации факта нацеленности входящих в него органов на обеспечение безопасности только лишь государства. Во-вторых, - к его ограниченности лишь федеральным сегментом государственного аппарата. В-третьих, - к невозможности его точного определения ввиду недостаточного уровня законодательного закрепления участия тех или иных органов в рассматриваемом направлении деятельности ${ }^{5}$.

Кроме того, хотелось бы отметить фактическое исключение из содержания данного элемента возможности использования правозащитного потенциала институтов гражданского общества, да и самих граждан Российской Федерации и их объединений

\footnotetext{
4 См.: Стратегия национальной безопасности Российской Федерации до 2020 года (утв. Указом Президента РФ от 12 мая 2009 г. № 537) // С3 РФ. 2009. № 20. Ст. 2444.

5 Подробнее см.: Гунич С.В. Конституционно-правовые аспекты определения сил обеспечения национальной безопасности Российской Федерации // Конституционное и муниципальное право. 2013. № 6. С. 15-17.
} 
при обеспечении национальной безопасности. Так, например, следуя буквальному толкованию, из данного круга субъектов исключается такая форма самоорганизации граждан Российской Федерации, как российское казачество. Хотя формально члены казачьих обществ принимают на себя обязательства по несению государственной или иной, в том числе правоохранительной службы ${ }^{6}$. Однако, как следует из правовых предписаний, проходить они ее должны в соответствии с федеральным законом, который так до сих пор и не принят.

Несколько сглаживает ситуацию установление в Федеральном законе от 28 декабря 2010 г. № 390-Ф3 «О безопасности» в качестве одного из принципов обеспечения безопасности взаимодействие государственных органов с общественными объединениями, международными организациями и гражданами, а также указание на возможность их участия в реализации государственной политики в области обеспечения безопасности. Прогрессивным видением здесь отличается система стратегического планирования обеспечения общественной безопасности. Так, основополагающий документ в данной сфере нацеливает на развитие конструктивного взаимодействия сил ее обеспечения также с институтами гражданского общества, гражданами Российской Федерации, иностранными гражданами и лицами без гражданства 7 Однако отметим, что никакими конкретными правами и обязанностями при этом указанные субъекты не наделяются.

В качестве объектов безопасности однозначно могут быть рассмотрены три социально-правовых категории - личность, общество и государство. Предмет, на который направлен механизм обеспечения национальной безопасности, определяется следующими составляющими: конституционные права, свободы, достойные качество и уровень жизни граждан, суверенитет, территориальная целостность и устойчивое развитие Российской Федерации, оборона и безопасность государства. Все это логически последовательно подводится под понятие национальной безопасности. На первый взгляд может показаться, что это и есть те самые ценности, которые отражены

\footnotetext{
6 См.: Федеральный закон от 5 декабря 2005 г. № 154-ФЗ (ред. от 2 июля 2013 г.) «О государственной службе российского казачества» // СЗ РФ. 2005. № 50. Ст. 5245.

7 См.: Концепция общественной безопасности в Российской Федерации (Утв. Президентом РФ 20 ноября 2013 г.) // URL: http://www.kremlin.ru.
}

в Преамбуле Конституции Российской Федерации, ради защиты которых она и принималась, необходимость обеспечения безопасности которых и ставилась во главу угла рассматриваемого механизма.

Безусловно, с этим сложно спорить. Однако вспомним, что развитие конституционализма и закрепление в основном законе основополагающих ценностей государства, на всех его этапах сопровождалось противостоянием личности и государственной власти. «Цель принятия конституции и ее последующего развития, как верно отмечает Д. Г. Шустров, - ограничение власти государства, ее рационализация, поставление государства в определенные конституционные рамки» ${ }^{8}$. Таким образом, представляется, что основная ценность любого государственно обособленного общества, то что в действительности является целью его создания и подлежит закреплению в конституционных актах это равная защита (достижение баланса) интересов личности, общества и государства в лице его органов и должностных лиц.

В современном же понимании национальная безопасность, как отмечает О. Г. Карпович, складывается из совокупной характеристики безопасности каждого из выделенных объектов 9 . И все бы ничего, если бы на практике не возникали ситуации, в которых необходимость обеспечения безопасности, а, следовательно, и интересов одного субъекта правоотношений (например, личности или государства) получает приоритет над интересами и безопасностью другого (общества или гражданина). Очевидно, что в данном случае может наблюдаться пересечение интересов выделенных субъектов, необходимость учета сбалансированности которых в законодательстве, тем не менее, не прослеживается.

Конституция Российской Федерации, провозглашая человека, его права и свободы в качестве высшей ценности, определяет и соответствующий вектор развития модернизированного российского государства. При этом она отнюдь не возводит их в некий неприкасаемый абсолют. В противном случае это могло бы повлечь за собой злоупотребление правом, что, как верно отметила Л. А. Шарнина, пред-

\footnotetext{
8 Шустров Д.Г. Государство как объект конституционноправового регулирования // Конституционное и муниципальное право. 2012. № 5. С. 14.

9 Карпович О.Г. Политика обеспечения национальной безопасности государства // Конституционное и муниципальное право. 2012. № 2. С. 24.
} 


\section{Национальная безопасность - № 4(33) • 2014}

ставляет собой неправомерное по сути, но формально законное деяние ${ }^{10}$. Вряд ли такое положение вещей будет соответствовать идеи правового государства. Так, например, еще Б. Н. Чичерин отмечал что «свобода не может считаться неприкосновенным правом, ибо закон всегда ее касается, ограничивая ее во имя чужой свободы и общественной пользы, и судьею этих ограничений может быть только сам закон как высшее начало, а не подчиненное ему лицо... Таким образом, нет ни одного человеческого права, которое было бы безусловно неприкосновенным ${ }^{11}$.

Данное высказывание не потеряло своей актуальности и в современном правоприменении, особенно в ситуации все нарастающей тяги к благам, которые сулит глобальное объединение. Именно в этой связи современными учеными и высшими государственными деятелями отмечается необходимость соотнесения наднациональных и национальных институтов - политических, финансовых, юридических и иных ${ }^{12}$. Их развитие, безусловно, должно исходить из баланса интересов субъектов, собственно и составляющих национальное единство, национальное богатство - человека и гражданина, общества и государства. Именно адекватное понимание данного баланса, его реализация в праве и в государственно-властной деятельности должно стать приоритетом развития современной России ${ }^{13}$.

Перекосы же в ту или иную сторону, поддержание состояния защищенности интересов одного субъекта в ущерб другому, создают ту основную угрозу, которая как раз и может быть рассмотрена в качестве прямой или косвенной возможности нанесения ущерба национальным интересам. Именно об этой угрозе, как представляется, высказывается Председатель Конституционного Суда Российской Федерации, говоря о недопустимости необоснованного возвышения интересов отдельной личности над необходимостью выполнения публичной функции по обеспечению обороноспособности государства и защиты общества (в связи с принятием Европейским

10 Шарнина Л.А. Злоупотребление конституционными правами и злоупотребление полномочиями: общее и особенное // Конституционное и муниципальное право. 2012. № 12. С. 10.

11 Чичерин Б.Н. Психологическая теория права // Вопросы философии и психологии. Кн. 55. 1900. С. 377.

12 См.: Зорькин В.Д. Предел уступчивости // URL://www. rg.ru/2010/10/29/zorkin.html (09.01.2014)

13 См.: Медведев Д.А. 20 лет: путь к осознанию права // URL:// www.rg.ru/2013/12/10/medvedev.html (09.01.2014) судом постановления от 7 октября 2010 года по делу «Константин Маркин против России»). Именно об этой угрозе предупреждал и Б. Н. Чичерин, говоря о том, что «истинно человеческая свобода не есть свобода животного, находящегося на воле, а свобода гражданская, подчиненная общему закону» ${ }^{14}$.

Таким образом, становится очевидным, что в качестве предмета должны выступать блага перечисленных объектов механизма обеспечения национальной безопасности, не умаляющие ценности друг друга, не посягающие на их существо. Деятельность же субъектов этого механизма по поддержанию состояния их защищенности необходимо выстраивать на началах соблюдения баланса жизненно важных интересов личности, общества и государства. Закрепление подобного принципа обеспечения безопасности в современном законодательстве, к сожалению, отсутствует. А ведь известно, к каким перегибам может привести деятельность по защите в угоду одного объекта без учета необходимости обеспечения реализации сформировавшейся воли другого. Думается, что именно совокупность сбалансированных интересов личности, общества и государства в различных сферах общегосударственной жизни должна быть положена в основу при определении национальных интересов государства. Действующие же нормативные правовые акты четкостью такого понимания не отличаются.

Так, Стратегия национальной безопасности Российской Федерации до 2020 года (далее Стратегия), в качестве национальных интересов почему-то определяет совокупность внутренних и внешних потребностей государства в обеспечении защищенности и устойчивого развития личности, общества и государства. Таким образом, создается возможность формулирования вывода, согласно которому функционирование всего механизма обеспечения национальной безопасности будет сведено, опять-таки, к защите потребностей лишь государства. Ведь наивно будет отрицать, что система обеспечения национальной безопасности, в первую очередь, направлена на защиту именно национальных интересов. Именно они должны ставиться во главу угла всей правозащитной деятельности.

Тем самым, оставив попытки установления, регламентации и защиты баланса интересов рас-

14 Чичерин Б.Н. Философия права // Чичерин Б.Н. Избр. труды. С. 77. 
сматриваемых объектов, государство, как обязанный субъект по его обеспечению, идет по пути нивелирования и возведения их в зависимость от своей воли. Ведь по существу, государство указанной потребности может и не ощущать. Однако это не свидетельство того, что национальные интересы одномоментно утрачивают свою бытность, поскольку остаются потребности как минимум личности и общества, а также и государства в сфере их взаимодействия и обеспечения жизнедеятельности. В сфере функционирования конституционных ценностей, наконец. Таким образом, представляется, что национальные интересы Российской Федерации - это более широкая правовая категория, чем она определяется действующими нормами, с необходимостью включающая в себя указание на обязанность защиты баланса интересов личности, общества и государства. Именно нарушение такого баланса, как представляется, может быть рассмотрено в качестве угрозы национальной безопасности Российской Федерации.

Методы и направления рассматриваемого механизма могут быть обозначены посредством характеристики средств как одной их составляющих системы обеспечения национальной безопасности, а также основных приоритетов национальной безопасности и приоритетов устойчивого развития. Первые, как представляется, непосредственным образом связаны с силами обеспечения национальной безопасности и могут быть использованы ими в своей повседневной деятельности. В качестве таковых Стратегия предлагает рассматривать технологии, а также технические, программные, лингвистические, правовые и организационные средства, включая телекоммуникационные каналы.

Действительно, всем входящим в систему обеспечения национальной безопасности субъектам присуща деятельность, которая в той или иной мере задействует перечисленные средства. Однако на первый взгляд может показаться, что они могут быть использованы лишь для сбора, формирования, обработки, передачи или приема информации о состоянии национальной безопасности и мерах по ее укреплению. Все-таки думается, что это относится лишь к телекоммуникационным каналам, а такая видимость создается из-за неудачной формулировки повествовательного предложения. Ведь как можно адекватно ответить на возникающую вовне или внутри государства угрозу, лишь производя какие-либо манипуляции с указанной информацией?
Безусловно, субъекты, входящие в систему национальной безопасности, должны иметь возможность использования всей палитры присущих им методов и средств для обеспечения состояния защищенности национальных интересов. Их использование должно отвечать принципу соразмерности возможным последствиям реализации предотвращаемой угрозы. Сожаление, однако, вызывает то, что в Стратегии не получило отражения место самих мер в системе обеспечения национальной безопасности. Как представляется, именно они определяют методы обеспечения безопасности, а также перечень задействуемых при этом средств.

Примерный перечень таких мер все же получил огласку при закреплении принципа системности и комплексности их применения в Федеральном законе «O безопасности» ${ }^{15}$. Тем не менее, в практической деятельности может возникнуть сложность соотнесения перечисляемых в Стратегии средств обеспечения национальной безопасности с используемыми мерами, в особенности такими как политические, дипломатические и некоторые другие. Думается, что как раз последние носят характер предупредительных и именно их использованию отдается приоритет в целях обеспечения безопасности. Однако определить, какие при этом могут быть использованы средства, представляется весьма затруднительным.

Основные приоритеты национальной безопасности Российской Федерации и приоритеты устойчивого развития также находят отражение в Стратегии. Базовые принципы, приоритетные направления, цели и задачи реализации этих стратегических национальных приоритетов регламентированы, кроме того, рядом правовых документов стратегического характера. Так, планирование деятельности по обеспечению национальной обороны, как основного приоритета национальной безопасности, строится на основе положений Военной доктрины Российской Федерации ${ }^{16}$, по обеспечению государственной безопасности - на основе Концепции внешней политики Российской Федерации ${ }^{17}$, деятельность по обеспечению общественной безопасности исходит из

\footnotetext{
15 См.: Федеральный закон от 28 декабря 2010 г. № 390-Ф3 «О безопасности // СЗ РФ. 2011. № 1. Ст. 2.

16 Утв. Указом Президента РФ от 5 февраля 2010 г. № 146 // СЗ РФ. 2010. № 7. Ст. 724.

17 Утв. Президентом РФ 12 февраля 2013 г. // URL:http:// www.mid.ru/brp_4.nsf/0/6D84DDEDEDBF7DA644257B16005 1BF7F (09.01.2014)
} 


\section{Национальная безопасность - № 4(33) • 2014}

Концепции общественной безопасности Российской Федерации ${ }^{18}$.

Подобного рода официальные документы в качестве правовой основы стратегического планирования государственной политики в той или иной сфере деятельности, с необходимостью содержат указание на Конституцию Российской Федерации, а также общепризнанные принципы и нормы международного права и международные договоры Российской Федерации. Все это свидетельствует, в том числе, и об интеграции отечественной правовой системы в международные механизмы обеспечения безопасности и неприкосновенности интересов защищаемых объектов. Отрадно, что внутригосударственный акт конституционного характера все же занимает первое место в иерархии указанных норм права. Данный факт, безусловно, заслуживает особого внимания при отстаивании именно национальных интересов. Подобное закрепление способно придать доминирующее положение конституционным ценностям перед возможностью навязывания воли других государств. В противном случае это само по себе способно воплотить в реальность гегемонию интересов сто- ронников однополярного мира и породить угрозу национальной безопасности разнонаправленных в своем развитии государств.

Таким образом, проведенный анализ показывает, что функционирование механизма обеспечения национальной безопасности в Российской Федерации должно осуществляться с опорой на конституционные ценности. Целью при этом должно стать обеспечение баланса интересов личности, общества и государства в их неразрывном единстве. Комплекс взаимосвязанных методов по упреждению или снижению угроз национальной безопасности должен исходить из приоритета мер предупредительного характера, позволяющих не только адекватно противостоять актуальным угрозам безопасности, но и обеспечивать равновесие предвосхищаемого результата и защищаемых ценностей. При обеспечении состояния защищенности личности, общества и государства необходимо привлекать возможности всех правозащитных институтов, в том числе граждан и их объединений. Основой для выстраивания характеризуемого механизма, безусловно, должна стать Конституция Российской Федерации.

\section{Библиография:}

1. Федеральный закон от 28 декабря 2010 г. № 390-Ф3 «О безопасности // СЗ РФ. 2011. № 1. Ст.

2. Федеральный закон от 5 декабря 2005 г. № 154-ФЗ (ред. от 2 июля 2013 г.) «О государственной службе российского казачества» // С3 РФ. 2005. № 50. Ст. 5245.

3. Военная доктрина Российской Федерации (утв. Указом Президента РФ от 5 февраля 2010 г. № 146) // С3 РФ. 2010. № 7. Ст. 724.

4. Стратегия национальной безопасности Российской Федерации до 2020 года (утв. Указом Президента РФ от 12 мая 2009 г. № 537) // С3 РФ. 2009. № 20. Ст. 2444.

5. Концепция внешней политики Российской Федерации (утв. Президентом РФ 12 февраля 2013 г.) // URL:http://www.mid.ru/brp_4.nsf/0/6D84DDEDEDBF7DA644257B160051BF7F (09.01.2014)

6. Концепция общественной безопасности в Российской Федерации (утв. Президентом РФ 20 ноября 2013 г.) // URL:http://www.kremlin.ru/acts/19653 (09.01.2014)

7. Гунич С.В. Конституционно-правовые аспекты определения сил обеспечения национальной безопасности Российской Федерации // Конституционное и муниципальное право. 2013. № 6. С. 15-17.

8. Зорькин В.Д. Предел уступчивости // URL://www.rg.ru/2010/10/29/zorkin.html (09.01.2014)

9. Карпович О.Г. Политика обеспечения национальной безопасности государства // Конституционное и муниципальное право. 2012. № 2. С. 23-26.

10. Медведев Д.А. 20 лет: путь к осознанию права // URL://www.rg.ru/2013/12/10/medvedev.html (09.01.2014)

11. Общая теория национальной безопасности: Учебник / Под общ. ред. А. А. Прохожева. Изд. 2 / М.: Изд-во РАГС, 2005.

12. Ростовщиков И.В. Права личности в России: их обеспечение и защита органами внутренних дел. Волгоград, 1997.

\footnotetext{
18 Утв. Президентом РФ 20 ноября 2013 г. // URL:http://www. kremlin.ru/acts/19653 (09.01.2014)
} 
13. Словарь Русского языка. Т. 2. М., 2002.

14. Чичерин Б.Н. Психологическая теория права // Вопросы философии и психологии. Кн. 55. 1900.

15. Чичерин Б.Н. Философия права // Чичерин Б. Н. Избр. труды.

16. Шарнина Л.А. Злоупотребление конституционными правами и злоупотребление полномочиями: общее и особенное // Конституционное и муниципальное право. 2012. № 12. С. 9-15.

17. Шустров Д.Г. Государство как объект конституционно-правового регулирования // Конституционное и муниципальное право. 2012. № 5. С. 13-20.

18. Грудцына Л.Ю., Петров С.М. Власть и гражданское общество в России: взаимодействие и противо-стояние // Административное и муниципальное право. - 2012. - 1. - С. 19-29.

19. Р.П. Сипок Субъекты обеспечения государственной безопасности Российской Федерации // Национальная безопасность / nota bene. - 2013. - 1. - C. 4-11. DOI: 10.7256/2073-8560.2013.01.1.

20. Е. А. Белокрылова О некоторых юридико-технических проблемах обеспечения национальной безопасности в свете общих положений Федерального закона от 28 декабря 2010 г. №390-Ф3 «О безопасности» // Национальная безопасность / nota bene. - 2011. - 5. - C. 34-44.

21. Г. А. Колобова Политико-государственные механизмы: теоретико-методологические аспекты // Право и политика. - 2011. - 7. - С. 1206-1211.

22. Ниязматова М.А. Административно-правовое регулирование национальной безопасности. // Административное и муниципальное право. - 2010. - 10. - С. 60-63.

23. Мальцев В.А. О выделении категории «интерес» в сферах обеспечения различных видов безопасности (на основе обобщения административно-правовых и конституционно-правовых и норм европейских государств) // Административное и муниципальное право. - 2012. - 2. - С. 43-52.

24. Г. А. Колобова Развитие российской государственной стратегии обеспечения экономической безопасности в постсоветский период // Национальная безопасность / nota bene. - 2012. - №4. - C. 13-21. URL: http:// www.nbpublish.com/go_to_article.php?id=21332.

\section{References:}

1. Federal'nyi zakon ot 28 dekabrya 2010 g. № 390-FZ «O bezopasnosti // SZ RF. 2011. № 1. St.

2. Federal'nyi zakon ot 5 dekabrya 2005 g. № 154-FZ (red. ot 2 iyulya 2013 g.) «O gosudarstvennoi sluzhbe rossiiskogo kazachestva» // SZ RF. 2005. № 50. St. 5245.

3. Voennaya doktrina Rossiiskoi Federatsii (utv. Ukazom Prezidenta RF ot 5 fevralya 2010 g. № 146) // SZ RF. 2010. № 7. St. 724.

4. Strategiya natsional'noi bezopasnosti Rossiiskoi Federatsii do 2020 goda (utv. Ukazom Prezidenta RF ot 12 maya 2009 g. № 537) // SZ RF. 2009. № 20. St. 2444.

5. Kontseptsiya vneshnei politiki Rossiiskoi Federatsii (utv. Prezidentom RF 12 fevralya 2013 g.) // URL:http://www. mid.ru/brp_4.nsf/0/6D84DDEDEDBF7DA644257B160051BF7F (09.01.2014)

6. Kontseptsiya obshchestvennoi bezopasnosti v Rossiiskoi Federatsii (utv. Prezidentom RF 20 noyabrya 2013 g.) // URL:http://www.kremlin.ru/acts/19653 (09.01.2014)

7. Gunich S.V. Konstitutsionno-pravovye aspekty opredeleniya sil obespecheniya natsional'noi bezopasnosti Rossiiskoi Federatsii // Konstitutsionnoe i munitsipal'noe pravo. 2013. № 6. S. 15-17.

8. Zor'kin V.D. Predel ustupchivosti // URL://www.rg.ru/2010/10/29/zorkin.html (09.01.2014)

9. Karpovich O.G. Politika obespecheniya natsional'noi bezopasnosti gosudarstva // Konstitutsionnoe i munitsipal'noe pravo. 2012. № 2. S. 23-26.

10. Medvedev D.A. 20 let: put' k osoznaniyu prava // URL://www.rg.ru/2013/12/10/medvedev.html (09.01.2014)

11. Obshchaya teoriya natsional'noi bezopasnosti: Uchebnik / Pod obshch. red. A. A. Prokhozheva. Izd. 2 / M.: Izdvo RAGS, 2005.

12. Rostovshchikov I.V. Prava lichnosti v Rossii: ikh obespechenie i zashchita organami vnutrennikh del. Volgograd, 1997.

13. Slovar' Russkogo yazyka. T. 2. M., 2002.

14. Chicherin B.N. Psikhologicheskaya teoriya prava // Voprosy filosofii i psikhologii. Kn. 55. 1900. 
DOI: $10.7256 / 2073-8560.2014 .4 .10672$

При цитировании этой статьи сноска на доі обязательна

\section{Национальная безопасность - № 4(33) • 2014}

15. Chicherin B.N. Filosofiya prava // Chicherin B. N. Izbr. trudy.

16. Sharnina L.A. Zloupotreblenie konstitutsionnymi pravami i zloupotreblenie polnomochiyami: obshchee i osobennoe // Konstitutsionnoe i munitsipal'noe pravo. 2012. № 12. S. 9-15.

17. Shustrov D.G. Gosudarstvo kak ob"ekt konstitutsionno-pravovogo regulirovaniya // Konstitutsionnoe i munitsipal'noe pravo. 2012. № 5. S. 13-20.

18. Grudtsyna L.Yu., Petrov S.M. Vlast' i grazhdanskoe obshchestvo v Rossii: vzaimodeistvie i protivo-stoyanie // Administrativnoe i munitsipal'noe pravo. - 2012. - 1. - S. 19-29.

19. R.P. Sipok Sub"ekty obespecheniya gosudarstvennoi bezopasnosti Rossiiskoi Federatsii // Natsional'naya bezopasnost' / nota bene. - 2013. - 1. - S. 4-11. DOI: 10.7256/2073-8560.2013.01.1.

20. E. A. Belokrylova O nekotorykh yuridiko-tekhnicheskikh problemakh obespecheniya natsional'noi bezopasnosti v svete obshchikh polozhenii Federal'nogo zakona ot 28 dekabrya 2010 g. №390-FZ «O bezopasnosti» // Natsional'naya bezopasnost' / nota bene. - 2011. - 5. - S. 34-44.

21. G. A. Kolobova Politiko-gosudarstvennye mekhanizmy: teoretiko-metodologicheskie aspekty // Pravo i politika. - 2011. - 7. - S. 1206-1211.

22. Niyazmatova M.A. Administrativno-pravovoe regulirovanie natsional'noi bezopasnosti. // Administrativnoe i munitsipal'noe pravo. -2010 . - 10. - S. 60-63.

23. Mal'tsev V.A. O vydelenii kategorii «interes» v sferakh obespecheniya razlichnykh vidov bezopasnosti (na osnove obobshcheniya administrativno-pravovykh i konstitutsionno-pravovykh i norm evropeiskikh gosudarstv) // Administrativnoe i munitsipal'noe pravo. - 2012. - 2. - S. 43-52.

24. G. A. Kolobova Razvitie rossiiskoi gosudarstvennoi strategii obespecheniya ekonomicheskoi bezopasnosti v postsovetskii period // Natsional'naya bezopasnost' / nota bene. - 2012. - №4. - S. 13-21. URL: http://www. nbpublish.com/go_to_article.php?id=21332. 